\title{
Strain Sensing Coatings for Large Composite Structures Based on 2D MXene Nanoparticles
}

\author{
Gediminas Monastyreckis $\left.{ }^{1}{ }^{(}\right)$, Anastasiia Stepura ${ }^{2}$, Yaryna Soyka ${ }^{2}$, Hanna Maltanava $\left.{ }^{3}{ }^{(}\right)$, Sergey K. Poznyak ${ }^{3} \mathbb{C}$ \\ Mária Omastová ${ }^{2}$, Andrey Aniskevich 4 (D) and Daiva Zeleniakiene ${ }^{1, *(D)}$ \\ 1 Department of Mechanical Engineering, Kaunas University of Technology, Studentu St. 56, \\ 51424 Kaunas, Lithuania; gediminas.monastyreckis@ktu.edu \\ 2 Polymer Institute, Slovak Academy of Sciences, Dúbravská cesta 9, 84541 Bratislava, Slovakia; \\ anastasiia.stepura@savba.sk (A.S.); upolyaso@savba.sk (Y.S.); maria.omastova@savba.sk (M.O.) \\ 3 Research Institute for Physical Chemical Problems, Belarusian State University, 220030 Minsk, Belarus; \\ maltanava@bsu.by (H.M.); poznyak@bsu.by (S.K.P.) \\ 4 Institute for Mechanics of Materials, University of Latvia, Jelgavas str. 3, LV-1004 Riga, Latvia; \\ andrey.aniskevich@pmi.lv \\ * Correspondence: daiva.zeleniakiene@ktu.lt
}

check for updates

Citation: Monastyreckis, G.; Stepura, A.; Soyka, Y.; Maltanava, H.; Poznyak, S.K.; Omastová, M.; Aniskevich, A.; Zeleniakiene, D. Strain Sensing Coatings for Large Composite Structures Based on 2D MXene Nanoparticles. Sensors 2021, 21, 2378. https://doi.org/10.3390/s21072378

Academic Editor: Nandika Anne D'Souza

Received: 13 March 2021

Accepted: 26 March 2021

Published: 29 March 2021

Publisher's Note: MDPI stays neutral with regard to jurisdictional claims in published maps and institutional affiliations.

Copyright: (c) 2021 by the authors. Licensee MDPI, Basel, Switzerland. This article is an open access article distributed under the terms and conditions of the Creative Commons Attribution (CC BY) license (https:/ / creativecommons.org/licenses/by/ $4.0 /)$.

\begin{abstract}
Real-time strain monitoring of large composite structures such as wind turbine blades requires scalable, easily processable and lightweight sensors. In this study, a new type of strainsensing coating based on 2D MXene nanoparticles was developed. $\mathrm{A} \mathrm{Ti}_{3} \mathrm{C}_{2} \mathrm{~T}_{\mathrm{z}}$ MXene was prepared from $\mathrm{Ti}_{3} \mathrm{AlC}_{2} \mathrm{MAX}$ phase using hydrochloric acid and lithium fluoride etching. Epoxy and glass fibre-reinforced composites were spray-coated using an MXene water solution. The morphology of the MXenes and the roughness of the substrate were characterised using optical microscopy and scanning electron microscopy. MXene coatings were first investigated under various ambient conditions. The coating experienced no significant change in electrical resistance due to temperature variation but was responsive to the 301-365 nm UV spectrum. In addition, the coating adhesion properties, electrical resistance stability over time and sensitivity to roughness were also analysed in this study. The electromechanical response of the MXene coating was investigated under tensile loading and cyclic loading conditions. The gauge factor at a strain of $4 \%$ was 10.88 . After 21,650 loading cycles, the MXene coating experienced a $16.25 \%$ increase in permanent resistance, but the response to loading was more stable. This work provides novel findings on electrical resistance sensitivity to roughness and electromechanical behaviour under cyclic loading, necessary for further development of MXene-based nanocoatings. The advantages of MXene coatings for large composite structures are processability, scalability, lightweight and adhesion properties.
\end{abstract}

Keywords: MXenes; coatings; strain sensors; electrical properties; cyclic loading

\section{Introduction}

In the past decade, the demand for nanosensors and electrically conductive polymer composites has grown considerably [1,2]. The tunability of properties based on nanoparticle materials and their mixtures can meet the requirements for various electronic devices and sensors. Currently, one of the largest known 2D nanoparticle families is the MXenes [3,4]. The most studied MXene particle is the titanium carbide $\mathrm{Ti}_{3} \mathrm{C}_{2} \mathrm{~T}_{\mathrm{z}}$, which has shown excellent mechanical and electrical properties (both in pristine form and in polymer composites) from nanoindentation measurements [5], molecular dynamics simulations [6], and finite element simulations [7,8]. Despite the relatively low van der Waals forces between 2D nanoflakes [9], pure MXene films have shown very high tensile strengths (590 MPa for a $980 \mathrm{~nm}$ thick film), which was obtained using large-diameter aligned flakes and the blade-casting method [10]. These properties can be influenced by different delamination methods $[11,12]$. During the etching and delamination process, the flake size and thickness 
of MXene particles can differentiate [13]. In addition, surface functional groups $\left(\mathrm{T}_{\mathrm{z}}\right)$, such as $-\mathrm{O},-\mathrm{OH}$, and $-\mathrm{F}[14]$ (which are responsible for adhesion and wettability properties), can be modified during the process. Experimental research and finite element modelling have shown that MXenes adhere to epoxies and polymers [15-17]. Easily processable and scalable methods, such as spray coating [18], vacuum filtration [19], 3D printing [20] and casting [10], have shown that MXenes are also very attractive nanoparticles for coatings and thin-film applications. MXenes have already been investigated and have revealed good results for Li-ion batteries [21], organic solar cells [22], electromagnetic interference shielding [23] and supercapacitors [24].

The unique multilayered and porous structure of MXene films can cause a highly sensitive response to deformation and morphology changes. Owing to the molecular intercalation between the nanolayers, MXene films behave as very sensitive multi-gas sensors [25] and humidity sensors [26]. Furthermore, MXene aerogel foams and other layered polymer nanocomposites can be used as ultra-sensitive pressure sensors with detection limits of up to $100 \mathrm{~Pa}$ [27]. Sandwich-type nanolaminates and nanosensors developed from a mixture of 2D nanoflakes, nanowires, and nanospheres [28-30] have shown a very wide strain-sensing range owing to their enhanced electrical conductivity and flake-to-flake sliding ability. One of the most sensitive strain sensors was obtained using MXene-intercalated textile yarns. Knittable and washable MXene-coated yarns have been shown to have ultra-sensitive strain responses with a gauge factor $\left(\mathrm{GF}_{152} \%\right.$ at a strain of $152 \%$ ) of up to 12,900 [31]. Another study was performed with MXene-silver nanowire coatings under tensile loading [28], where the $\mathrm{GF}_{5 \%}$ reached approximately 10 . The same experiment was performed with graphene-silver nanowire coatings, where $\mathrm{GF}_{5 \%}$ reached only 2.5 [32]. Meanwhile, carbon nanotube (CNT) modified polymers [33] possessed much lower strain sensing capability, where $\mathrm{GF}_{5 \%}$ varied between 0.1 and 0.25 .

The electromechanical mechanism of nanoparticle-based strain sensors is well explained by an analytical approach [34]. Surface topography images also provide in-depth details on how the structure of the nanocoating behaves under a wide range of deformations $(0-60 \%)$ [32]. It was also found that the electrical sensitivity was enhanced by electron tunnelling effects [35], which mostly occur when the distance between the nanoparticles is less than $3 \mathrm{~nm}$. An analytical approach describing the tunnelling effect explains how electric resistance can change under nanoscale deformations [36].

Traditional sensors, such as strain gauges, accelerometers, piezoelectric transducers, and fibre optic cables, have been used for wind turbine monitoring [37]. These sensors typically experience adhesion problems and application difficulties, requiring precise sensor calibration and complex signal processing [38]. Despite this, fibre Bragg grating (FBG) optical sensors are widely used due to their most accurate strain measurements. FBG sensors are is still being improved by materials such as magnetostrictive Terfenol-D $\left(\mathrm{Tb}_{0.3} \mathrm{Dy}_{0.7} \mathrm{Fe}_{1.92}\right)$, with whom the sensitivity of the system is improved by a factor of 4 [39].

Until now, MXenes have not been investigated as strain-sensing coatings for fibrereinforced polymer composites. The aim of this study is to develop an easily processable and scalable MXene coating that can detect the low strain values typical for fibre-reinforced composites. The main tasks were to characterise the morphology and uniformity of the coating, investigate the response to environmental conditions (such as temperature and UV irradiation), analyse the surface roughness influence on sensing performance and study the sensing behaviour under tensile loading and cyclic loading conditions. The strain sensing ability of the MXene coating was based on the change in electrical resistance. Simple spray-coating methods and electrical resistance monitoring systems were a priority during the experiments.

\section{Materials and Methods}

\subsection{Materials}

$\mathrm{Ti}_{3} \mathrm{C}_{2} \mathrm{~T}_{\mathrm{Z}}$ MXenes were prepared from $\mathrm{Ti}_{3} \mathrm{AlC}_{2}$ MAX phase with a particle size of $<40 \mu \mathrm{m}$ and purity of $98 \mathrm{wt} . \%$ (MRC, Kiev, Ukraine) using a previously documented 
method [12]. The etching solvents used were hydrochloric acid (37 wt.\%, Merck, Darmstadt, Germany) and lithium fluoride (>99 wt.\%, Sigma Aldrich, Munich, Germany). LiF was mixed with $\mathrm{HCl}$ to generate $\mathrm{HF}$ in the system. The MAX phase was slowly added and stirred for $24 \mathrm{~h}$. The multilayer MXene sediment was further delaminated using 99 wt.\% LiCl (Sigma Aldrich, Munich, Germany). The resulting solution was centrifuged 10-15 times at $3500 \mathrm{rpm}$ and washed with deionised water until the $\mathrm{pH}$ of the supernatant reached 6.5. The concentration of the delaminated MXenes in the supernatant was $0.335 \mathrm{mg} / \mathrm{mL}$, but it was further centrifuged until the concentration reached $3.3 \mathrm{mg} / \mathrm{mL}$ to be more suitable for the spraying process.

The thermosetting epoxy resin Bisphenol F-epichlorohydrin (Biresin ${ }^{\circledR}$ CR122, Sika AG, Baar, Switzerland) and an amine curing agent (Biresin $\left.{ }^{\circledR} \mathrm{CH} 122-5\right)$ were mixed at a ratio of 10:3. Epoxy tensile specimens (ISO-527-2-5A) were cast in silicone moulds. Glass fibre-reinforced polymer (GFRP) tensile specimens and sandwich-type GFRP specimens were prepared for adhesion tests by hand-layup and vacuum bagging methods. GFRP tensile specimens $(15 \mathrm{~cm} \times 1.5 \mathrm{~cm})$ were made of 5 plies of twill-weave $2 / 2\left(163 \mathrm{~g} / \mathrm{m}^{2}\right)$ Interglas 92110 (Porcher Industries, Erbach, Germany), and adhesion specimens $(14 \mathrm{~cm} \times 2.5 \mathrm{~cm})$ were made of a total of 8 plies and $4 \mathrm{~mm}$ thick AIREX C70.75 foam (Airex AG, Sins, Switzerland). All specimens were cured at room temperature for $24 \mathrm{~h}$ and post-cured in a convection oven for $5 \mathrm{~h}$ at $100{ }^{\circ} \mathrm{C}$. Additionally, epoxy samples were roughened in the $\mathrm{Y}$ direction (parallel to loading), $\mathrm{X}$ direction (perpendicular to loading), and $\mathrm{YX}$ direction (roughened in both directions) using P280 sandpaper (52.2 $\mu \mathrm{m}$ average particle diameter). All samples were plasma-treated and spray-coated with a water-based MXene solution, as described below.

\subsection{Preparation of MXene Coating}

To enhance the adhesion between the epoxy substrate and MXenes, a surface plasma treatment was performed using a Zepto Diener low-pressure plasma cleaner (Diener Electronic GmbH \& Co. KG, Ebhausen, Germany) and a K1050X RF plasma cleaner (Quorum Technologies, Laughton, UK). The samples were treated under vacuum with no additional gases for 3 min with $100 \mathrm{~W}$ power at $40 \mathrm{kHz}$ frequency. The water contact angle was reduced from $68.7^{\circ}$ (for pristine epoxy) to $25.3^{\circ}$ (for the modified epoxy surface). Another treatment was performed in a vacuum with an oxygen and argon enriched atmosphere for 3 min with $100 \mathrm{~W}$ at $13.56 \mathrm{MHz}$. The contact angle was reduced to $20.1^{\circ}$. After the epoxy surface plasma treatment, water-based MXenes were sprayed using a Sparmax HB-040 airbrush with a $0.4 \mathrm{~mm}$ diameter nozzle and a Sparmax DC-25X 2.07 bar compressor with $0.1 \mathrm{~mL} / \mathrm{s}$ paint yield (Anest Iwata Sparmax Co., Taipei, Taiwan). The MXene coating was applied by spraying for $10 \mathrm{~s}$ at a distance of $15 \mathrm{~cm}$, which naturally dried over 5-10 s at room temperature. Copper wires were directly soldered onto the MXene films using the commercially available electrically conductive polymer Protopasta (Protoplant, Inc., Vancouver, WA, USA). This polymer is made from a mixture of polylactic acid (PLA) (4043D PLA, Natureworks, Minnetonka, MN, USA) and carbon black (CB). The volume resistivity of the polymer is $30 \Omega \mathrm{cm}$, and the melting point is $155^{\circ} \mathrm{C}$. The soldering needle temperatures were set to $200{ }^{\circ} \mathrm{C}$, similar to the $3 \mathrm{D}$ printer nozzle temperatures. The soldered wires were additionally covered with a thin layer of silver paste. The distance between the silver paste contacts for both the epoxy and GFRP samples was $30 \mathrm{~mm}$. The epoxy specimen sprayed with MXenes and a monitoring system (described in Section 2.3) are presented in Figure 1. 


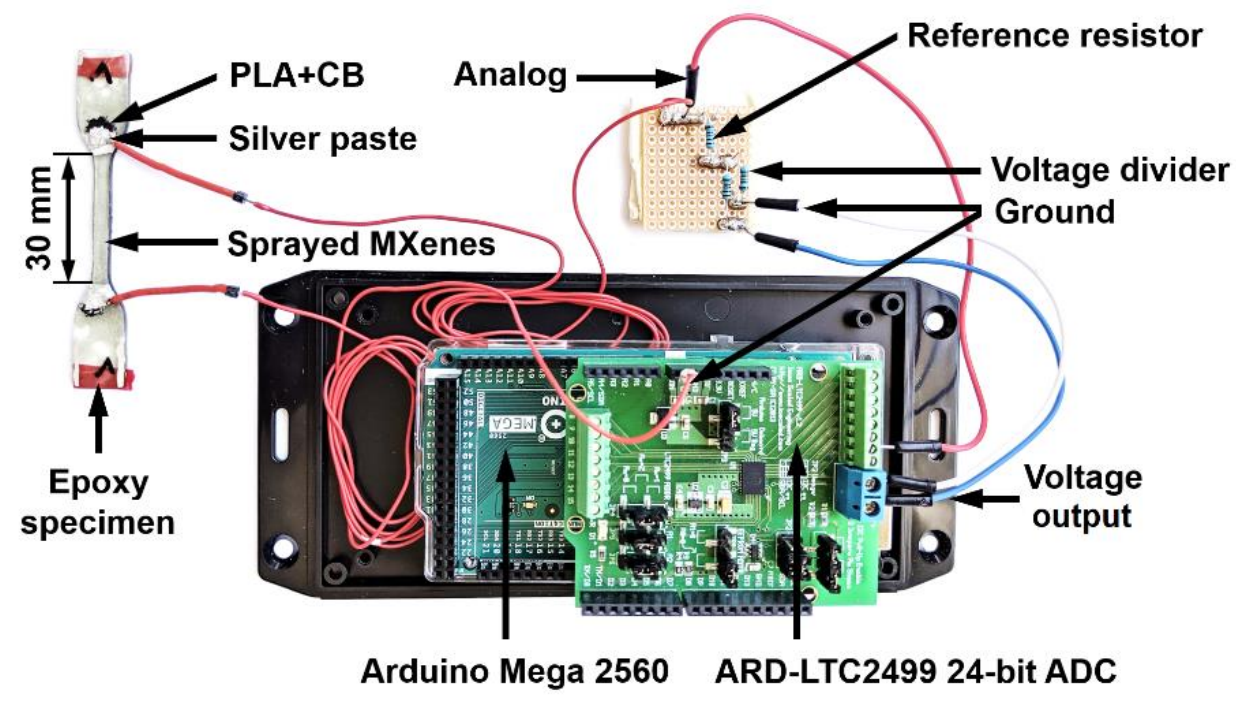

Figure 1. MXene-coated epoxy specimen and electrical resistance measurement system.

\subsection{Characterisation and Testing Equipment}

$X$-ray photoelectron spectroscopy characterisation of the same $\mathrm{Ti}_{3} \mathrm{AlC}_{2} \mathrm{MAX}$ phase and $\mathrm{Ti}_{3} \mathrm{C}_{2} \mathrm{~T}_{\mathrm{z}}$ MXenes was previously reported by Zukiene et al. [16]. The thickness and topography of the MXene coatings were characterised using scanning electron microscopy (SEM) (JEOL JSM 6610, JEOL Ltd., Tokyo, Japan). Gold-coated samples were measured under high-vacuum mode with an accelerating voltage of $15 \mathrm{kV}$.

The homogeneity of the MXene coating after plasma treatment and the roughness of the substrate were investigated using a Leica DVM6 optical microscope (Leica Microsystems, Wetzlar, Germany). 3D optical topographical scanning was performed using the image rendering software LAS X (Leica Microsystems), based on the stacking of 2D images in the $\mathrm{Z}$ direction.

Tensile and fatigue tests were performed using Tinius Olsen H25 KT (Tinius Olsen, Salfords, UK) and Instron ElectroPuls E10000T (Instron, Norwood, MA, USA) equipment, respectively. Deformations in the longitudinal direction between four strain markings ( $2.5 \mathrm{~cm}$ distance) and transversal deformations between six strain markings ( $4 \mathrm{~mm}$ distance), were measured using Manta G-146B visual extensometer (Allied Vision Technologies, Stadtroda, Germany). Peeling on epoxy samples $(5 \mathrm{~cm} \times 0.5 \mathrm{~cm})$ covered with the MXene coating was investigated using simple household adhesive tape. Pull-out tests of MXenecoated sandwich-type GFRP specimens were performed using an Adheometr PM 420/63 under ISO-4624 standards. For the UV light absorbance experiment, a UV DRT230 lamp with a 301-365 nm emission wavelength and a surface power density of 3-7 $\mathrm{mW} / \mathrm{cm}^{2}$ was used. Experiments were performed on an MXene-coated sandwich-type GFRP specimen $(13.5 \mathrm{~cm} \times 2.5 \mathrm{~cm})$. The response of the MXene coating to direct sunlight was measured under a clear sky with a solar elevation angle of $54^{\circ}$ (Riga, Latvia).

The temperature and initial electrical resistance values were monitored using a Fluke 287 True-RMS logging multimeter (Fluke Corporation, Everett, WA, USA). The temperature of MXenes was measured using a temperature probe soldered to aluminium foil $(0.3 \mathrm{~mm} \times 25 \times 30 \mathrm{~mm})$, which was pressed to a $0.2 \mathrm{~mm}$ thick protective epoxy layer on top of the MXene coating. An MXene coating area of the same size $(25 \mathrm{~mm} \times 30 \mathrm{~mm})$ was heated with 10-90 V (DC) using AX-12001DBL external power supply (Transfer Multisort Elektronik, Łódź, Poland). For the tensile-tensile fatigue tests, electrical resistance values were measured using Arduino Mega 2560 microcontroller (Figure 1) and ATmega2560 microchip (Arduino, Turin, Italy). Additionally, a 24-bit analogue-to-digital converter (ARD-LTC2499, Iowa Scaled Engineering, Elbert, CO, USA) with a precise $4.096 \mathrm{~V}$ output voltage and $7 \mathrm{~Hz}$ measurement frequency was used for high-accuracy electrical resistance 
measurements. The electrical resistance monitoring during mechanical loading was based on the voltage difference between a single reference resistor and the MXene coating.

\section{Results}

\subsection{MXene Coating Topography}

The morphology of the MXene flakes and the coating was studied using SEM. The average thickness of the coating was approximately $1 \mu \mathrm{m}$, as evident in the cross-sectional view of the fractured epoxy sample presented in Figure 2a. A plasma-treated smooth epoxy sample coated with $M X e n e s$ is presented in Figure $2 b$ (top view). $A \mathrm{Ti}_{3} \mathrm{C}_{2} \mathrm{~T}_{\mathrm{z}}$ flake with a size of $20 \mu \mathrm{m} \times 10 \mu \mathrm{m}$ can be seen, while sizes, ranging from 1 to $5 \mu \mathrm{m}$ are the most common, as it was reported in previous SEM analysis [16]. The MXene-coated GFRP sample is shown in Figure 2c (top view), in which glass fibre filament markings and MXene flake edges can be seen.
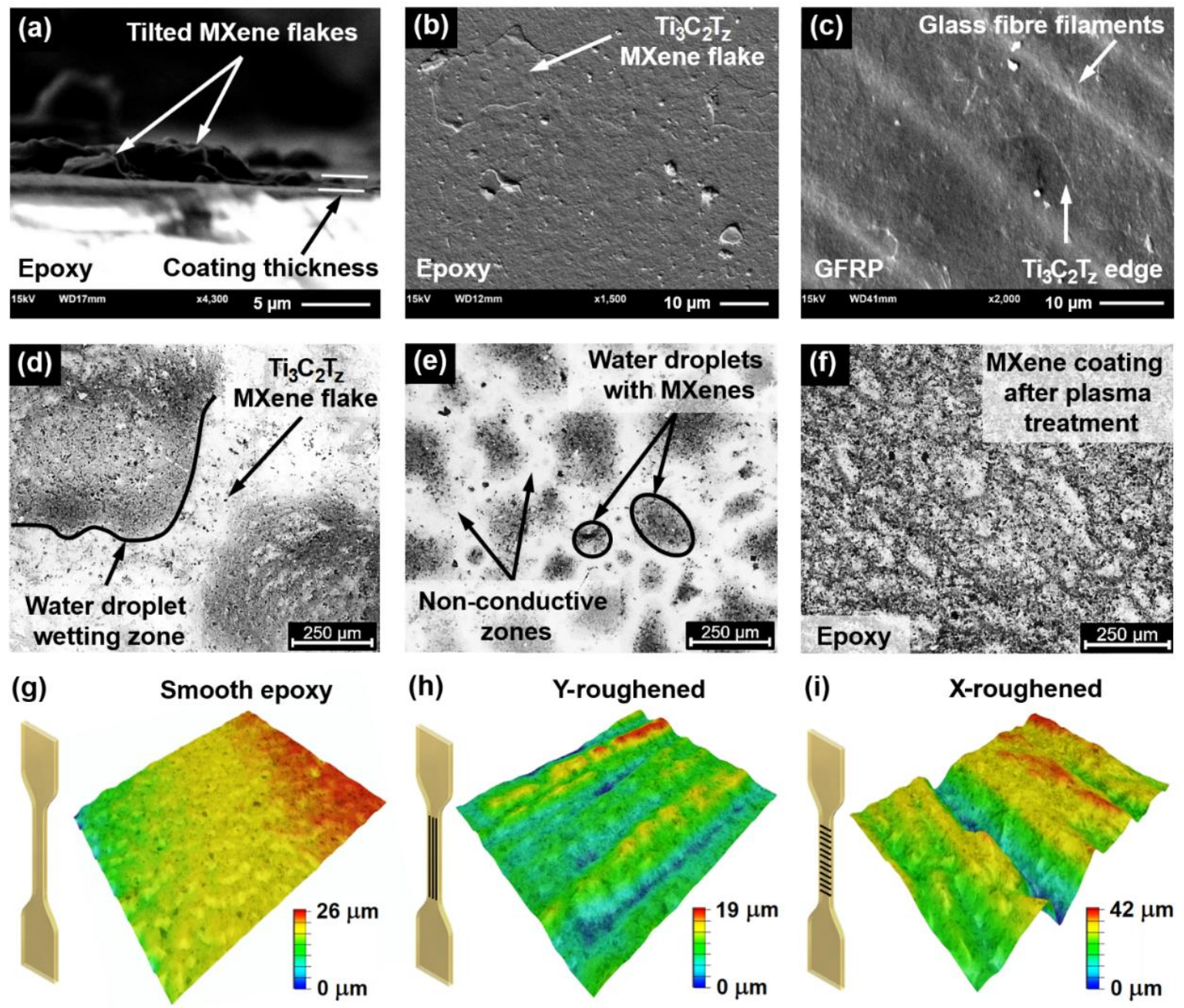

Figure 2. Scanning electron microscopy images of the sprayed MXenes: (a) thickness of the coating; (b) topography of MXenes on epoxy, and (c) glass fibre-reinforced polymer samples. Optical microscopy images of the MXene coatings: (d) sprayed for $2 \mathrm{~s}$ at $3 \mathrm{~cm}$; (e) sprayed for $10 \mathrm{~s}$ at $15 \mathrm{~cm}$; and (f) sprayed for $10 \mathrm{~s}$ at $15 \mathrm{~cm}$ on a plasma-treated epoxy sample. Optical topography images of epoxy samples that were $(\mathbf{g})$ smooth, $(\mathbf{h})$ roughened in the $\mathrm{Y}$ direction, and (i) roughened in the $\mathrm{X}$ direction.

Owing to the optical transparency of the epoxy and MXenes [40], the overall quality of the coating was analysed using an optical microscope with an external light source. First, small water droplets containing higher (darker areas) and lower (lighter areas) concentrations of MXene flakes were observed in optical microscopy images (Figure 2d). 
The primary reason for this effect was the hydrophobic epoxy surface. In addition, the size of these droplets and coating uniformity depended on the spraying time and nozzle distance. For example, when sprayed for $2 \mathrm{~s}$ at $3 \mathrm{~cm}$ from the surface, water droplets were $250-500 \mu \mathrm{m}$ in size (Figure 2d), while spraying for $10 \mathrm{~s}$ at $15 \mathrm{~cm}$ reduced the droplet size to $50-250 \mu \mathrm{m}$ (Figure 2e). Plasma treatment was performed to enhance the hydrophilic properties of the epoxy surface, which increased the conductivity and uniformity of the coating (Figure 2f). The sensitivity of strain sensors based on nanoparticles depends on the morphology of the substrate surface [41]. To investigate this effect, epoxy tensile specimens were roughened in the $Y, X$, and $Y X$ directions. 3D optical topography images $(600 \mu \mathrm{m} \times 450 \mu \mathrm{m})$ are presented in Figure $2 \mathrm{~g}-\mathrm{i}$, and detailed average roughness values are presented in Section 3.4

\subsection{MXene Coating Adhesion and Stability}

The adhesion to epoxy and the stability of the MXene coatings were investigated using SEM images and electrical resistance changes during every peel-off attempt with adhesive tape. An SEM image of the sample before peeling is presented in Figure 3a, where an MXene coating with small fragments can be seen. After the first peel-off, the surface of the MXene coating became smooth and no fragments, rupture spots, or debonding from the epoxy was observed (Figure $3 b$ ). However, the relative electrical resistance increased with every peel-off attempt (Figure 3c). After the first peel-off, the relative resistance increased 3.2 times, and it increased 8.6 times after the fifth. After five peeling attempts, no damage to the coating was observed, which suggests that adhesion between the MXenes and the epoxy was strong, as mentioned in several previous studies [15-17]. To extend the adhesion experiments, an MXene coating pull-out test was performed (Figure $3 \mathrm{~d}$ ). $\mathrm{The}^{\mathrm{T}} \mathrm{Ti}_{3} \mathrm{C}_{2} \mathrm{~T}_{\mathrm{Z}}$ water solution was sprayed on a more rigid sandwich-type GFRP composite. In total, six pullout attempts were performed on two GFRP specimens, and an average pull-out stress of 2.14 MPa was obtained. Despite the pull-out, the inner area retained MXene flakes, whose electrical resistance increased roughly 19 times compared to the initial values (Figure $3 \mathrm{~d})$. Therefore, the actual pull-out stress (2.14 MPa) was obtained between MXene-MXene flakes in the perpendicular direction. This stress is roughly 10 times lower than the tensile strength of pure MXene-MXene films [42,43]. These results are very important for the further development of strain sensing MXene coatings.

Coatings based on $\mathrm{Ti}_{3} \mathrm{C}_{2} \mathrm{~T}_{\mathrm{Z}}$ MXenes tend to degrade by their oxidation to $\mathrm{TiO}_{2}$ in various exploitation conditions [44]. In this article, the MXene coating stability was investigated over a four-week period at room temperature (Figure 3e). The relative electrical resistance over four weeks of a sample peeled one time was 2.49, while that of a non-peeled sample was 3.80. This suggests that a coating with a smoother surface will oxidise slower owing to the smaller nanoparticle area exposed to air. The best electrical resistance stability of the MXene coatings was achieved with a protective epoxy layer. In comparison, the electrical resistance of the sample without a covering layer increased the fastest, and the resistance after four weeks was 3.7 times higher than that of the covered sample. Such oxidation rates of MXenes do not satisfy application requirements for sensors, where on the contrary, MAX phase-based sensors show long-term stability [45]. Therefore, the focus still remains on the development of new oxidation preventing methods such as hydrogen annealing [46] and L-ascorbic acid treatment [47], which have already shown positive effects. 

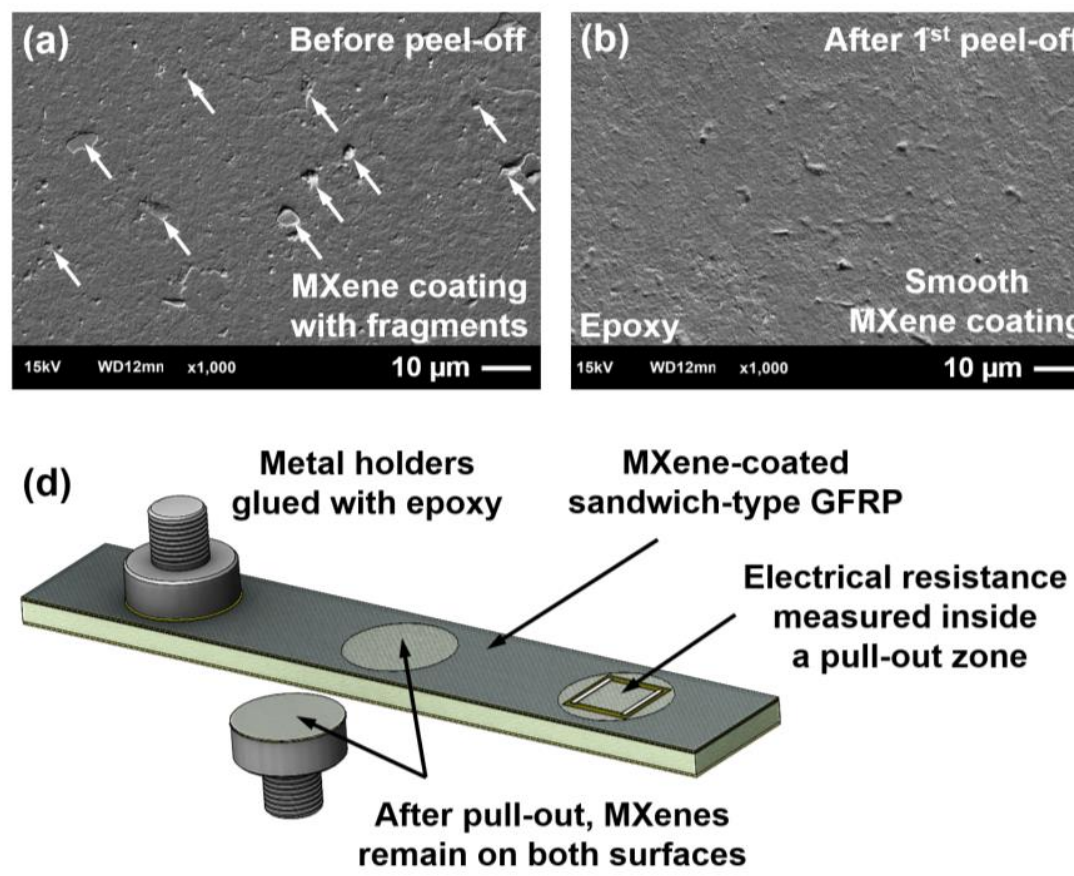
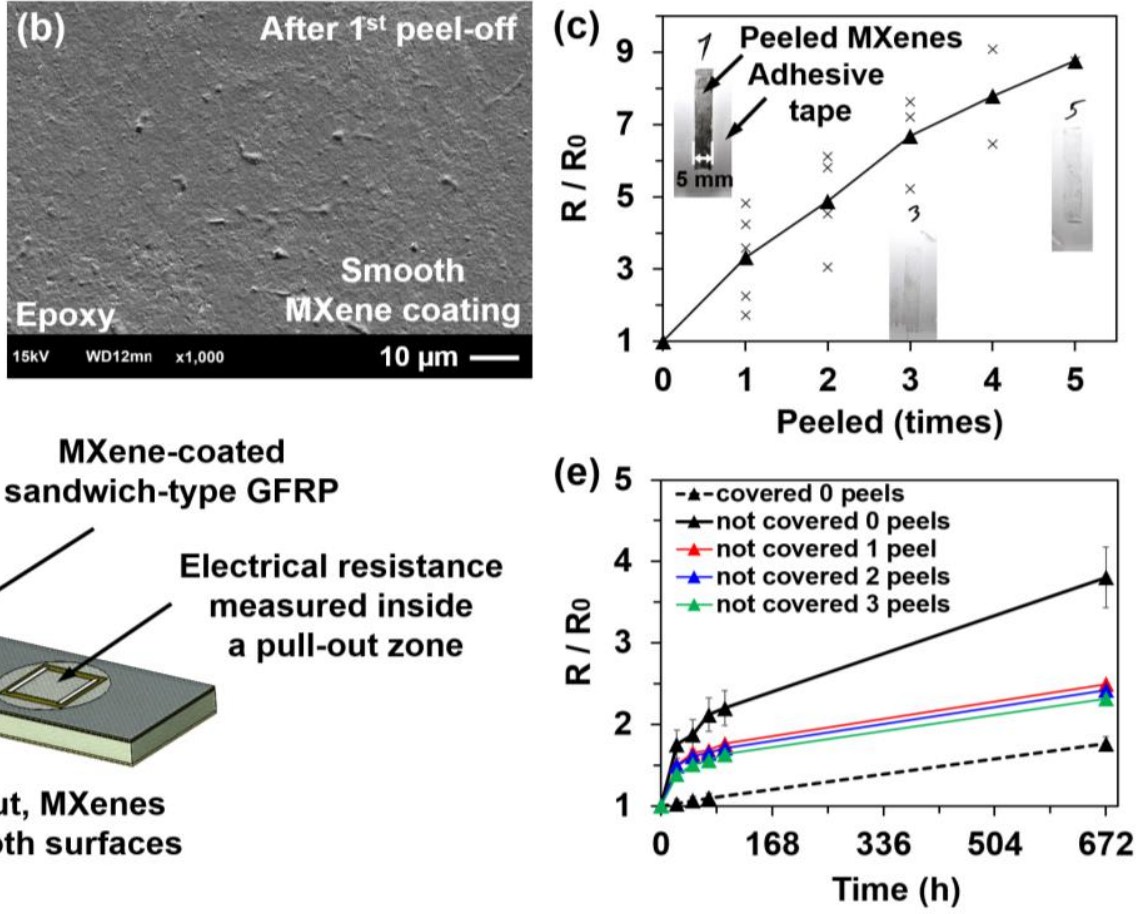

Figure 3. Scanning electron microscopyimages of the MXene coating (a) before peeling and (b) after the first peel-off attempt; (c) electrical resistance change during five peel-off attempts; (d) MXene coating pull-out test; and (e) electrical resistance change over a 4 week period.

\subsection{MXene Coating UV and Temperature Response}

Experiments were performed to understand deviations in the electrical signal from the MXene coatings due to ambient conditions, such as direct sunlight and temperature. Several studies have shown that MXene films can experience high heating temperatures $\left(114{ }^{\circ} \mathrm{C}\right)$ under an applied voltage of $6 \mathrm{~V}$ [48]. In this study, coating temperatures under $10-90 \mathrm{~V}$ were investigated. When $10 \mathrm{~V}$ was applied, the temperature of the MXenes only increased from 24 to $27^{\circ} \mathrm{C}$ (Figure 4a) owing to the high resistance of the coating $(0.91 \mathrm{k} \Omega)$. In comparison, at $50 \mathrm{~V}$, the coating temperature increased to $103.8^{\circ} \mathrm{C}$, and at $90 \mathrm{~V}$, the coating temperatures plateaued at $183.7^{\circ} \mathrm{C}$, which is close to the epoxy melting temperature. Detailed results of the temperature response under different voltages are presented in Figure 4a. The electrical resistance was measured after $50 \mathrm{~V}$ was applied and then removed, and the coating cooled naturally from 103.8 to $35.6{ }^{\circ} \mathrm{C}$ over $300 \mathrm{~s}$ (Figure $4 \mathrm{~b}$ ). During this process, the electrical resistance decreased to $0.8 \%$. The electric current was also monitored during the heating process with an applied voltage (Figure 4c). When the temperature of the coating reached $156{ }^{\circ} \mathrm{C}(70 \mathrm{~V})$, the resistance of the coating began to increase, and the electric current dropped. This occurred because of the softened epoxy surface, which resulted in a change in the morphology and a rearrangement of the MXene flakes. In addition, no degradation of $\mathrm{Ti}_{3} \mathrm{C}_{2} \mathrm{~T}_{\mathrm{Z}}$ could occur, according to previous thermogravimetric analysis [49], which shows that the MXene is thermally stable and loses only $4-7 \%$ of its weight at $700{ }^{\circ} \mathrm{C}$. 
(a)

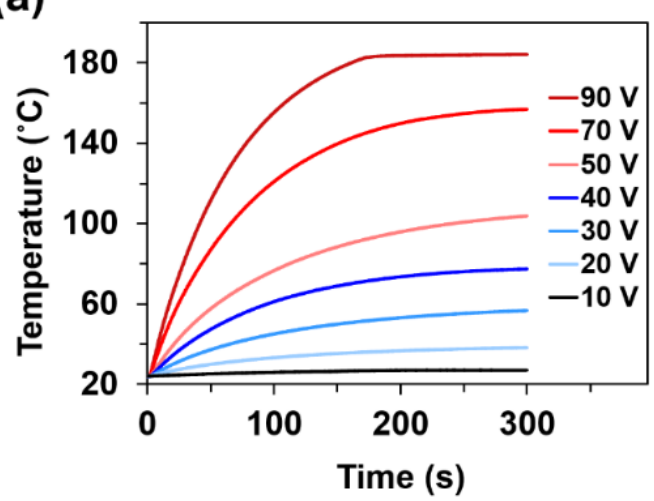

(c)

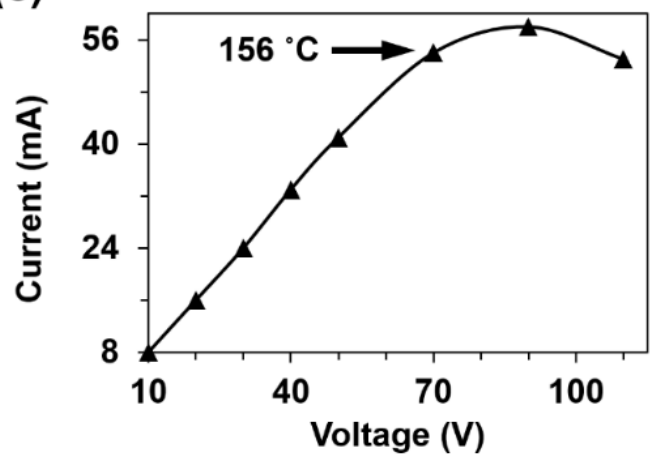

(b)

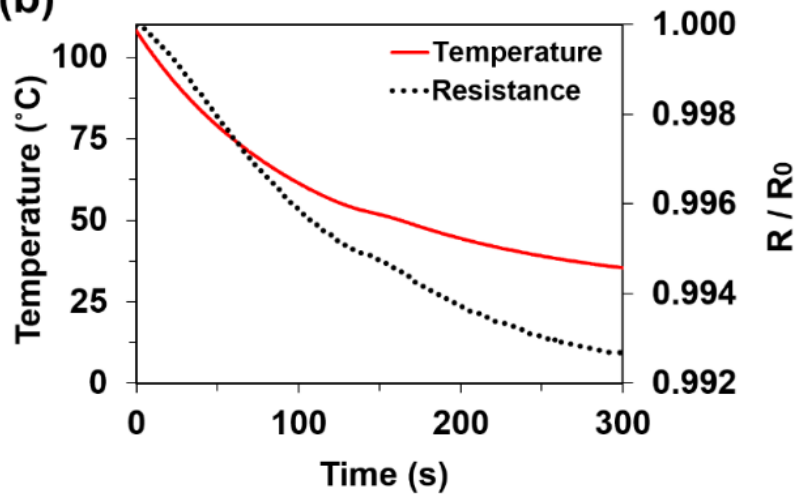

(d)

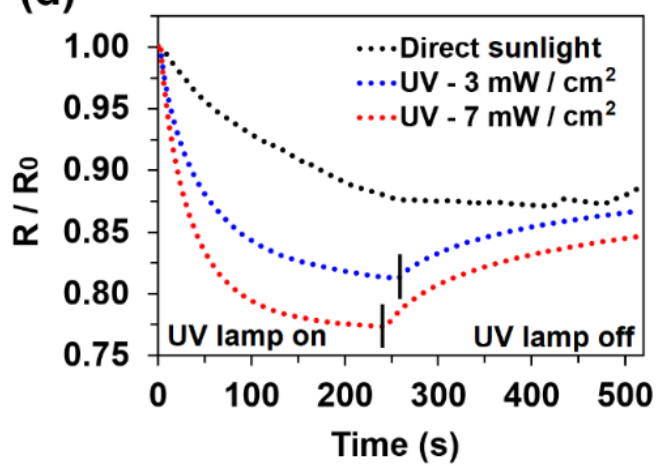

Figure 4. (a) Increase in the MXene coating temperature under different applied voltages; (b) change in the electrical resistance during the natural cooling process of the sample; (c) response of the electric current to applied voltage; and (d) relative electrical resistance response of the MXene coating to direct sunlight and UV irradiation.

As described in several articles [50], MXene and other nanoparticles, such as graphene, exhibit high absorbance in the $200-400 \mathrm{~nm}$ UV spectrum. Therefore, the electrical resistance response of the MXene coating to direct sunlight was measured. After 5 min under direct sunlight, the electrical resistance of the coating decreased by $12.5 \%$ (Figure $4 \mathrm{~d}$ ). Depending on the UV lamp irradiance intensity, the response of the coating reached a steady state after $4 \mathrm{~min}$, and the electrical resistance decreased by $22.7 \%$ at $7 \mathrm{~mW} / \mathrm{cm}^{2}\left(35^{\circ} \mathrm{C}\right.$ specimen temperature). These results are important because they help to avoid electrical signal disturbance due to ambient conditions. Therefore, tensile and fatigue tests were performed without daylight, and the temperatures of the samples were monitored during the testing.

\subsection{Tensile Tests of MXene-Coated Epoxy Specimens}

In this experiment, the electromechanical behaviour of MXene coatings under tensile loading was monitored on smooth and roughened epoxy samples. The average roughness values in the $X$ and $Y$ directions, initial resistance values $\left(R_{0}\right)$, resistance values at the sample breaking point $\left(\mathrm{R}_{\mathrm{b}}\right)$, and gauge factors at strains of $1 \%\left(\mathrm{GF}_{1 \%}\right)$ and $4 \%\left(\mathrm{GF}_{4} \%\right)$ of 4 samples with different roughness values $(0, Y, X$, and $Y X)$ are presented in Table 1 .

Table 1. Electrical resistance response of the MXene coatings during tensile tests.

\begin{tabular}{cccccc}
\hline $\begin{array}{c}\text { Roughening } \\
\text { Direction }\end{array}$ & $\begin{array}{c}\text { Average Roughness } \\
\text { in X/Y Directions }(\boldsymbol{\mu m})\end{array}$ & $\begin{array}{c}\mathbf{R}_{\mathbf{0}} \\
(\mathbf{k} \boldsymbol{\Omega})\end{array}$ & $\begin{array}{c}\mathbf{R}_{\mathbf{b}} \\
(\mathbf{k} \boldsymbol{\Omega})\end{array}$ & $\mathbf{G F}_{\mathbf{1} \%}$ & $\mathbf{G F}_{\mathbf{4}} \%$ \\
\hline 0 & 0.56 & 8.48 & 49.3 & 1.02 & 4.17 \\
$\mathrm{Y}$ & $0.68 / 2.31$ & 48.3 & 1049 & 1.12 & 4.81 \\
$\mathrm{X}$ & $2.54 / 1.32$ & 674 & 14924 & 1.29 & 10.88 \\
$\mathrm{YX}$ & $1.67 / 1.63$ & 647 & 3604 & 1.08 & 5.01 \\
\hline
\end{tabular}


The relative electrical resistance response of the MXene coatings to 5 initial loading cycles, with amplitudes of 10 to $50 \mathrm{MPa}$, are presented in Figure $5 \mathrm{a}$. A considerable difference in initial resistance was obtained between the smooth and X-roughened samples $(8.48 \mathrm{k} \Omega$ versus $674 \mathrm{k} \Omega$, respectively). In addition, the $X$-roughened sample with a roughness of $2.54 \mu \mathrm{m}$ had the highest $\mathrm{GF}_{1 \%}$ of 1.29 , while the smooth sample with an average roughness of $0.56 \mu \mathrm{m}$ showed only 1.02 (Figure $5 \mathrm{~b}$ ). Notable changes in the relative resistance curves for all the samples appeared between strains of $0.5 \%$ and $1.1 \%$ (Figure $5 b$ ). Previous research on pure MXene films under tensile conditions yielded similar fracture strain values, which are marked in the figure as MXene fracture points (FP): FP-1 [48], FP-2 [49], and FP-3 [42,43]. These results suggest that MXene flakes began to debond from one another as the resistance began to increase drastically. Another important comparison is presented in Figure $5 c, d$, which shows that the resistance behaviour on the smooth epoxy substrate was stable during cycling, while on the rough substrate, the values were more chaotic. These results help to understand the electrical signal response under different strain values as well as to illuminate how even a small difference in roughness can have a substantial impact on the coating sensitivity. For instance, MXene-silver nanowire coatings reached $\mathrm{GF}_{5 \%}$ of 10 [28], while in this research, depending on the roughness, $\mathrm{GF}_{4} \%$ was obtained in the range of 4.17-10.88.

(a)

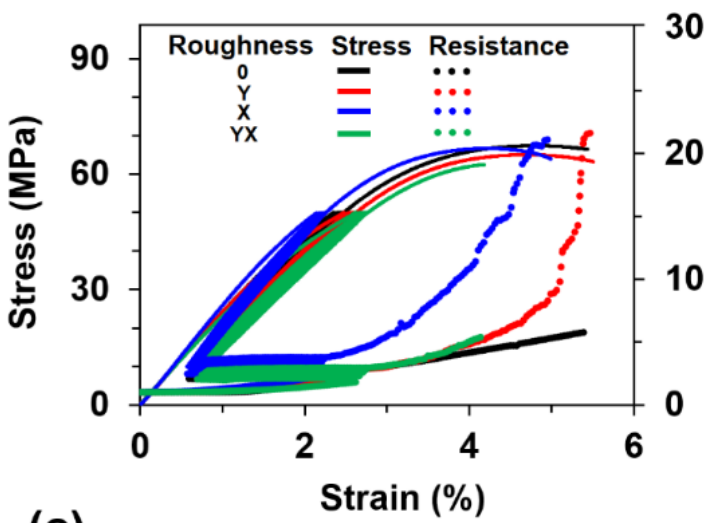

(c)

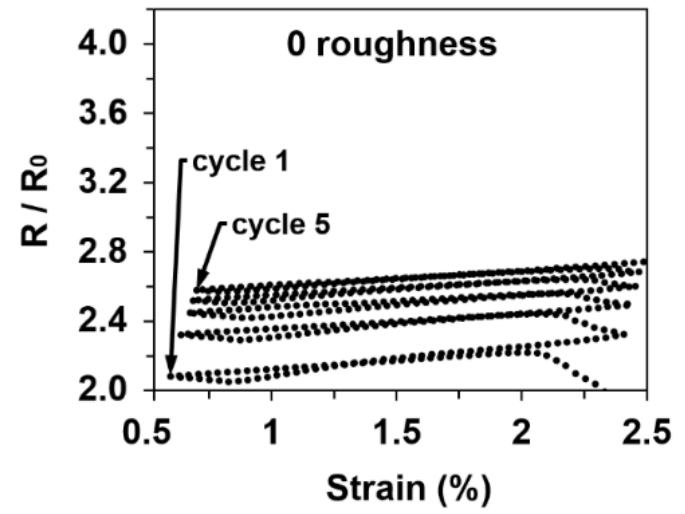

(b)

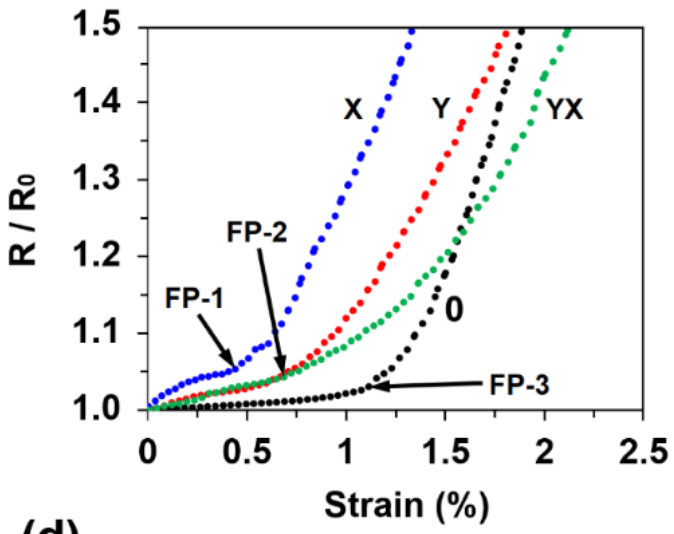

(d)

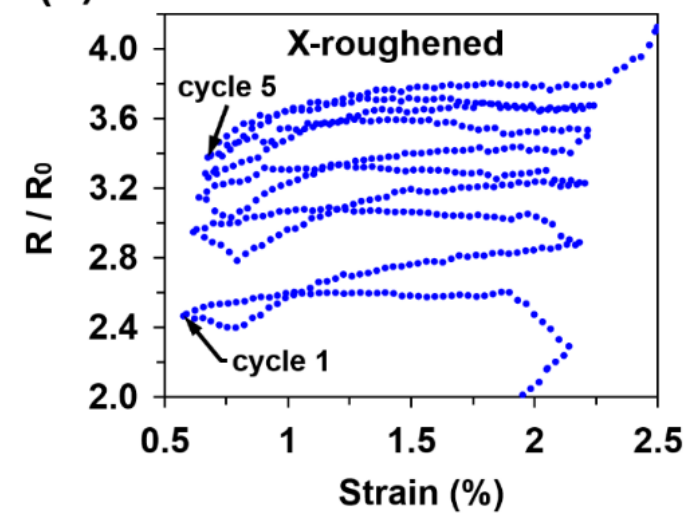

Figure 5. Results from tensile tests with five initial loading cycles on smooth and roughened MXene-coated epoxy samples: (a) mechanical response and relative electrical resistance measurements of four samples with different roughening; (b) magnified region showing the electrical resistance at low strains; and MXene resistance response under five loading cycles with 10-50 MPa amplitudes on (c) a smooth epoxy sample and (d) an X-roughened sample.

\subsection{Fatigue Tests of MXene-Coated Epoxy Specimens}

After the initial tensile tests, tensile-tensile fatigue tests were performed with smooth MXene-coated epoxy specimens. Loading cycles were performed in the elastic region of 
the specimens at $0.5 \mathrm{~Hz}$ and an $8.33-25 \mathrm{MPa}$ loading amplitude (0.31-0.97\% strain). The specimen temperatures were monitored throughout the tests and were maintained at $25^{\circ} \mathrm{C}$. The change in electrical resistance over 21,650 cycles can be seen in Figure 6a. The electrical resistance amplitude $(\Delta R)$ at the beginning of the fatigue test can be seen in the magnified region showing the first 100 cycles (Figure $6 \mathrm{~b}$ ), where $\Delta R$ was approximately $2 \%$. It is important to note that the electrical resistance permanently increased after every cycle, and after 21,650 loading cycles, the MXene coating experienced an irreversible resistance increase of $16.25 \%$. The last 50 cycles are shown in Figure $6 c$, where $\Delta R$ decreased from $2 \%$ to $1 \%$, which indicates that the coating became less sensitive. However, the important result was that the rate of increase of the irreversible resistance became much lower, i.e., the MXene coating electrical signal became more stable to mechanical loading. The results of the variation in the electrical resistance of the MXene coating over twenty-one thousand cycles under the same loading conditions are important for the development of signal processing algorithms and further coating improvements.

(a)

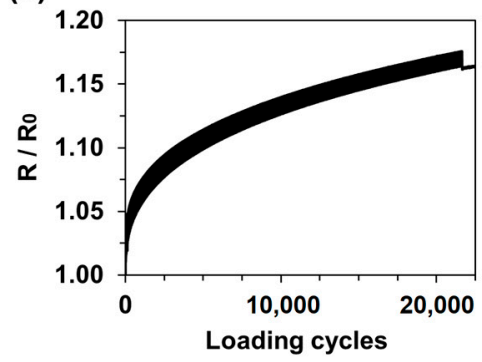

(b)

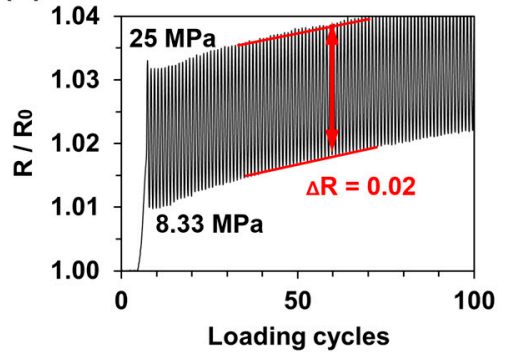

(c)

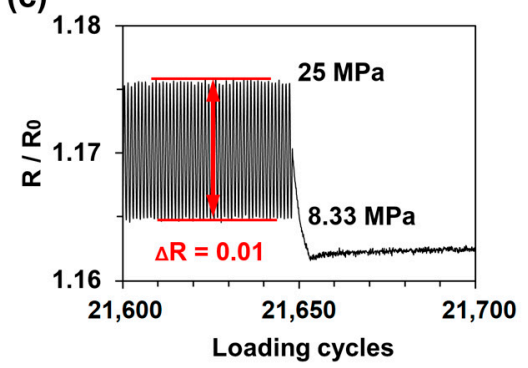

Figure 6. Fatigue test results of a smooth MXene-coated epoxy sample: (a) relative resistance during fatigue testing with an 8.33-25 MPa amplitude, and magnified regions showing (b) the first 100 cycles and (c) the last 50 cycles.

\subsection{Fatigue Tests of MXene-Coated GFRP Specimens}

The tensile-tensile fatigue response of the MXene coating was further investigated using $0^{\circ}$ and $45^{\circ}$ fibre angle GFRP specimens. The samples were first tested until fracture, and tensile strengths of 393.3 and $120.3 \mathrm{MPa}$ and fracture strains of $2.86 \%$ and $6.98 \%$ were obtained for the $0^{\circ}$ and $45^{\circ}$ fibre specimens, respectively. The $\mathrm{GF}_{2 \%}$ of the $0^{\circ}$ specimen was 1.72 , and that of the $45^{\circ}$ specimen was 1.08 . The fatigue tests were performed at $0.5 \mathrm{~Hz}$ with a variable loading amplitude. Detailed loading properties are presented in Table 2 and labelled according to the loading steps (force, stress, and strain).

Table 2. Fatigue loading steps: loading amplitude, tensile stress, and tensile strain.

\begin{tabular}{cccc}
\hline Loading Step & Loading Amplitude (kN) & Tensile Stress (MPa) & Tensile Strain (\%) \\
\hline 0 & 0 & 0 & 0 \\
1 & $0.25-1.25$ & $33-165$ & $0.21-1.07$ \\
2 & $0.50-1.50$ & $66-198$ & $0.42-1.33$ \\
3 & $0.75-1.75$ & $99-231$ & $0.63-1.59$ \\
4 & $1.00-2.00$ & $132-264$ & $0.85-1.86$ \\
\hline
\end{tabular}

The fatigue tests of the MXene-coated $0^{\circ}$ and $45^{\circ}$ fibre angle GFRP specimens showed similar strain sensing tendencies; therefore, only the results of the $0^{\circ}$ specimen under different loading steps are presented in Figure 7a. In total, four loading step sequences (0-1-2-3-4-3-2-1-0) were applied. It can be observed that the MXene coating sensitivity to strain becomes more stable with repeated loading steps. First, the irreversible resistance increased at every loading step, but after several thousand cycles, the permanent resistance only increased during the fourth step, which had a high loading amplitude (Figure $7 \mathrm{~b}$ ). After four series of loading step sequences, the sample was loaded with low amplitude steps (1-2-1) (Figure 7c). During this stage, the strain sensing of the MXene coating was 
stable, and it was possible to identify the exact tensile stress (and strain) according to the relative resistance values. A magnified region showing the electrical resistance is presented in Figure $7 \mathrm{~d}$. The accuracy obtained using only a single reference resistor scheme with no additional filtering or amplification of the signal demonstrate that the MXenes are strain-sensitive nanoparticles. Although, the resistance amplitude at small strain regions $(0.21-1.07 \%)$ is not very high $(\Delta R=2.7 \%)$, when compared to CNT intercalated MXene sensors ( $\Delta R=5.5 \%$ at $0.2-1 \%$ strain) [29]. Pure MXene coatings can still be competitive due to their processability, scalability and good adhesion properties when compared to MXene-CNT nanocoatings.

(a)

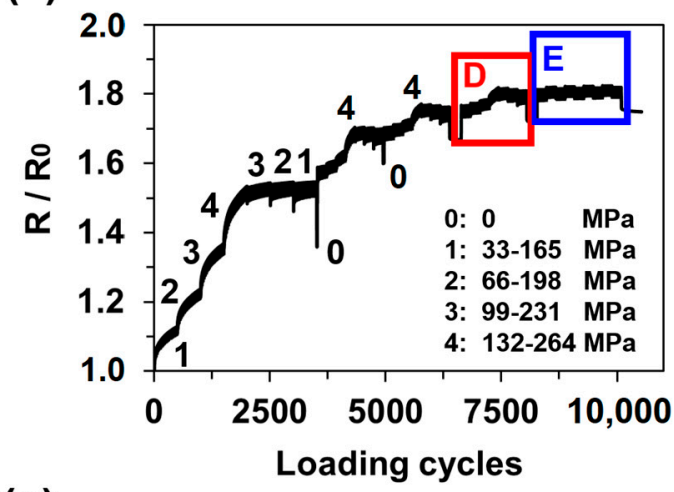

(c)

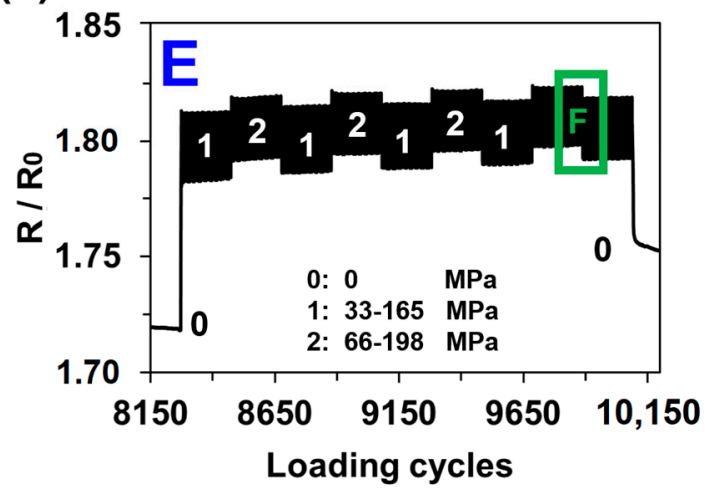

(b)

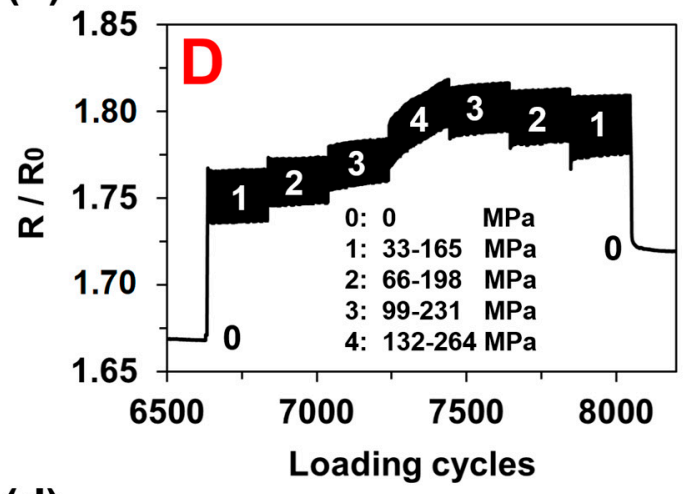

(d)

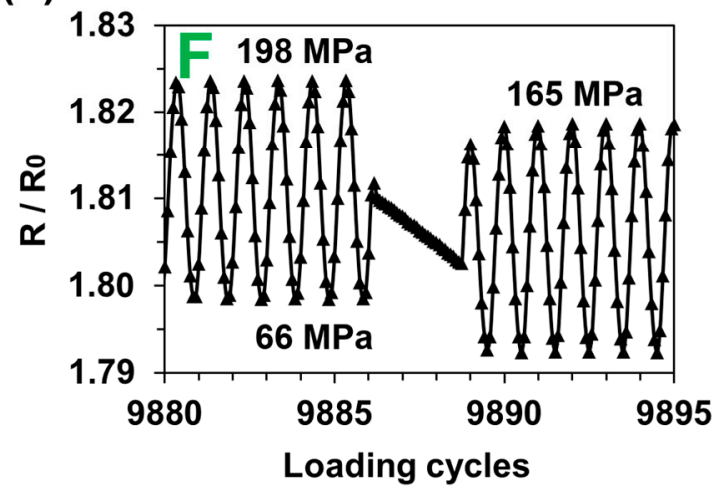

Figure 7. Fatigue test results for $\mathrm{MXene-coated} 0^{\circ}$ glass fibre-reinforced polymer specimen: (a) relative electrical resistance response under 10000 loading cycles with varying amplitude; (b) magnified region showing the loading step series 0-1-2-34-3-2-1-0; (c) magnified region showing the loading step series 1-2-1; and (d) magnified region showing the loading step change from 2 to 1 .

\section{Conclusions}

In this study, a comprehensive electromechanical investigation of MXene-coated epoxy and GFRP specimens was performed. $\mathrm{Ti}_{3} \mathrm{C}_{2} \mathrm{~T}_{\mathrm{Z}}$ was synthesised using $\mathrm{HCl}$ and $\mathrm{LiF}$ etching. A water-based MXene solution was sprayed onto plasma-treated epoxy and GFRP samples.

Before the tensile experiments, the response of MXene coatings to heating and UV irradiation was analysed. The MXene coating experienced no significant increase in electrical resistance until the epoxy substrate began to degrade at $156^{\circ} \mathrm{C}$. After 5 min under direct sunlight, the coating resistance decreased by $12.5 \%$ and reached a plateau. Under $301-365 \mathrm{~nm}$ UV light, the resistance decreased by $22.7 \%$.

To investigate the strain sensitivity behaviour of the MXene coating, epoxy samples were roughened in directions perpendicular and parallel to the tensile loading. The surface roughness was measured using 3D optical microscopy scanning, and the morphology of the MXenes was characterised using SEM. The MXene strain sensitivity was primarily 
dependant on the perpendicular roughness, where the gauge factor at $4 \%$ strain was 10.88 , while that of the parallel roughness was 4.81 .

The increase in the electrical resistance of the MXene coatings over time, durability to peeling, and MXene adhesion to the epoxy surface was also studied. The pull-out stress obtained between MXene-MXene particles in the perpendicular direction was 2.14 MPa.

The main focus of this study was to investigate the electrical resistance response of MXene-coated epoxy and GFRP samples under tensile-tensile fatigue loading. After 21,650 loading cycles at a constant loading amplitude, the MXene coating on the epoxy experienced a $16.25 \%$ increase in permanent resistance. GFRP samples were tested under varying amplitudes with high tensile loads. After 10,000 cycles, the electrical resistance of the MXene coating permanently increased by 1.8 times, but the response to loading was more stable and equal to $2.7 \%$ resistance change at a strain region of $0.21-1.07 \%$.

These results demonstrate that MXenes are a viable material for ultra-thin, scalable, and easily processed strain-sensing coatings for large fibre-reinforced composite structures.

Author Contributions: Conceptualisation, G.M., M.O., A.A. and D.Z.; methodology, G.M., A.S., Y.S., H.M., S.K.P., M.O., A.A. and D.Z.; software, G.M.; validation, G.M. and D.Z.; formal analysis, G.M., S.K.P. and D.Z.; investigation, G.M., A.S., Y.S., H.M., M.O., A.A. and D.Z.; resources, M.O., A.A. and D.Z.; data curation, G.M., A.S., Y.S. and H.M.; writing-original draft preparation, G.M.; writing-review and editing, A.S., Y.S., H.M., S.K.P., M.O., A.A. and D.Z.; visualisation, G.M., H.M. and D.Z.; supervision, S.K.P., M.O., A.A. and D.Z.; project administration, M.O., A.A. and D.Z.; funding acquisition, M.O., A.A. and D.Z. All authors have read and agreed to the published version of the manuscript.

Funding: This project received funding from the European Union's Horizon 2020 research and innovation program under the Marie Skłodowska-Curie grant agreement No. 777810.

Institutional Review Board Statement: Not applicable.

Informed Consent Statement: Not applicable.

Data Availability Statement: Not applicable.

Acknowledgments: Alena Opalkova Siskova is acknowledged for contributing to the SEM study.

Conflicts of Interest: The authors declare no conflict of interest.

\section{References}

1. Liu, H.; Li, Q.; Zhang, S.; Yin, R.; Liu, X.; He, Y.; Dai, K.; Shan, C.; Guo, J.; Liu, C.; et al. Electrically Conductive Polymer Composites for Smart Flexible Strain Sensors: A Critical Review. J. Mater. Chem. C 2018, 6, 12121-12141. [CrossRef]

2. Wang, B.; Facchetti, A. Mechanically Flexible Conductors for Stretchable and Wearable E-Skin and E-Textile Devices. Adv. Mater. 2019, 1901408. [CrossRef]

3. Gogotsi, Y.; Anasori, B. The Rise of MXenes. ACS Nano 2019, 13, 8491-8494. [CrossRef] [PubMed]

4. Venkateshalu, S.; Grace, A.N. MXenes-A New Class of 2D Layered Materials: Synthesis, Properties, Applications as Supercapacitor Electrode and Beyond. Appl. Mater. Today 2020, 18, 100509. [CrossRef]

5. Plummer, G.; Anasori, B.; Gogotsi, Y.; Tucker, G.J. Nanoindentation of Monolayer $\mathrm{Ti}_{n+1} \mathrm{C}_{\mathrm{n}} \mathrm{T}_{\mathrm{x}}$ MXenes via Atomistic Simulations: The Role of Composition and Defects on Strength. Comput. Mater. Sci. 2019, 157, 168-174. [CrossRef]

6. Borysiuk, V.N.; Mochalin, V.N.; Gogotsi, Y. Bending Rigidity of Two-Dimensional Titanium Carbide (MXene) Nanoribbons: A Molecular Dynamics Study. Comput. Mater. Sci. 2018, 143, 418-424. [CrossRef]

7. Kilikevičius, S.; Kvietkaitè, S.; Žukienè, K.; Omastová, M.; Aniskevich, A.; Zeleniakienè, D. Numerical Investigation of the Mechanical Properties of a Novel Hybrid Polymer Composite Reinforced with Graphene and MXene Nanosheets. Comput. Mater. Sci. 2020, 174, 109497. [CrossRef]

8. Zeleniakiene, D.; Monastyreckis, G.; Aniskevich, A.; Griskevicius, P. Deformation and Failure of MXene Nanosheets. Materials 2020, 13, 1253. [CrossRef]

9. Zhang, H.; Fu, Z.H.; Legut, D.; Germann, T.C.; Zhang, R.F. Stacking Stability and Sliding Mechanism in Weakly Bonded 2D Transition Metal Carbides by van Der Waals Force. RSC Adv. 2017, 7, 55912. [CrossRef]

10. Zhang, J.; Kong, N.; Uzun, S.; Levitt, A.; Seyedin, S.; Lynch, P.A.; Qin, S.; Han, M.; Yang, W.; Liu, J.; et al. Scalable Manufacturing of Free-Standing, Strong $\mathrm{Ti}_{3} \mathrm{C}_{2} \mathrm{~T}_{\mathrm{x}} \mathrm{MXene}$ Films with Outstanding Conductivity. Adv. Mater. 2020, 32, 2001093. [CrossRef]

11. Lipatov, A.; Alhabeb, M.; Lukatskaya, M.R.; Boson, A.; Gogotsi, Y.; Sinitskii, A. Effect of Synthesis on Quality, Electronic Properties and Environmental Stability of Individual Monolayer Ti3C2 MXene Flakes. Adv. Electron. Mater. 2016, 2, 1600255. [CrossRef] 
12. Alhabeb, M.; Maleski, K.; Anasori, B.; Lelyukh, P.; Clark, L.; Sin, S.; Gogotsi, Y. Guidelines for Synthesis and Processing of Two-Dimensional Titanium Carbide $\left(\mathrm{Ti}_{3} \mathrm{C}_{2} \mathrm{~T}_{\mathrm{x}}\right.$ MXene). Chem. Mater. 2017, 29, 7633-7644. [CrossRef]

13. Maleski, K.; Ren, C.E.; Zhao, M.Q.; Anasori, B.; Gogotsi, Y. Size-Dependent Physical and Electrochemical Properties of TwoDimensional MXene Flakes. ACS Appl. Mater. Interfaces 2018, 10, 24491-24498. [CrossRef] [PubMed]

14. Hope, M.A.; Forse, A.C.; Griffith, K.J.; Lukatskaya, M.R.; Ghidiu, M.; Gogotsi, Y.; Grey, C.P. NMR Reveals the Surface Functionalisation of $\mathrm{Ti}_{3} \mathrm{C}_{2}$ MXene. Phys.Chem.Chem.Phys. 2016, 18, 5099-5102. [CrossRef] [PubMed]

15. Monastyreckis, G.; Mishnaevsky Jr., L.; Hatter, C.B.; Aniskevich, A.; Gogotsi, Y.; Zeleniakiene, D. Micromechanical Modeling of MXene-Polymer Composites. Carbon N.Y. 2020, 162, 402-409. [CrossRef]

16. Zukiene, K.; Monastyreckis, G.; Kilikevicius, S.; Procházka, M.; Micusik, M.; Omastová, M.; Aniskevich, A.; Zeleniakiene, D. Wettability of MXene and Its Interfacial Adhesion with Epoxy Resin. Mater. Chem. Phys. 2021, 257, 123820. [CrossRef]

17. Hatter, C.B.; Shah, J.; Anasori, B.; Gogotsi, Y. Micromechanical Response of Two-Dimensional Transition Metal Carbonitride (MXene) Reinforced Epoxy Composites. Compos. Part B 2020, 182, 107603. [CrossRef]

18. Zhao, M.-Q.; Trainor, N.; Ren, C.E.; Torelli, M.; Anasori, B.; Gogotsi, Y. Scalable Manufacturing of Large and Flexible Sheets of MXene/Graphene Heterostructures. Adv. Mater. Technol. 2019, 4, 1800639. [CrossRef]

19. Yang, Y.; Shi, L.; Cao, Z.; Wang, R.; Sun, J. Strain Sensors with a High Sensitivity and a Wide Sensing Range Based on a Ti ${ }_{3} \mathrm{C}_{2} \mathrm{~T}_{\mathrm{x}}$ (MXene) Nanoparticle-Nanosheet Hybrid Network. Adv. Funct. Mater. 2019, 29, 1807882. [CrossRef]

20. Orangi, J.; Hamade, F.; Davis, V.A.; Beidaghi, M. 3D Printing of Additive-Free $2 \mathrm{D} \mathrm{Ti}_{3} \mathrm{C}_{2} \mathrm{~T}_{\mathrm{x}}(\mathrm{MXene})$ Ink for Fabrication of MicroSupercapacitors with Ultra-High Energy Densities. ACS Nano 2020, 14, 640-650. [CrossRef]

21. Tian, Y.; An, Y.; Feng, J. Flexible and Freestanding Silicon/MXene Composite Papers for High-Performance Lithium-Ion Batteries. ACS Appl. Mater. Interfaces 2019, 11, 10004-10011. [CrossRef]

22. Tang, H.; Feng, H.; Wang, H.; Wan, X.; Liang, J.; Chen, Y. Highly Conducting MXene-Silver Nanowire Transparent Electrodes for Flexible Organic Solar Cells. ACS Appl. Mater. Interfaces 2019, 11, 25330-25337. [CrossRef]

23. Yun, T.; Kim, H.; Iqbal, A.; Cho, Y.S.; Lee, G.S.; Kim, M.; Kim, S.J.; Kim, D.; Gogotsi, Y.; Kim, S.O.; et al. Electromagnetic Shielding of Monolayer MXene Assemblies. Adv. Mater. 2020, 32, 1906769. [CrossRef]

24. Wang, Z.; Qin, S.; Seyedin, S.; Zhang, J.; Wang, J.; Levitt, A.; Li, N.; Haines, C.; Ovalle-Robles, R.; Lei, W.; et al. High-Performance Biscrolled MXene/Carbon Nanotube Yarn Supercapacitors. Small 2018, 14, 1802225. [CrossRef] [PubMed]

25. Kim, S.J.; Koh, H.-J.; Ren, C.E.; Kwon, O.; Maleski, K.; Cho, S.; Anasori, B.; Kim, C.; Choi, Y.; Kim, J.; et al. Metallic Ti ${ }_{3} \mathrm{C}_{2} \mathrm{~T}_{\mathrm{x}}$ MXene Gas Sensors with Ultrahigh Signal-to-Noise Ratio. ACS Nano 2018, 12, 986-993. [CrossRef]

26. An, H.; Habib, T.; Shah, S.; Gao, H.; Patel, A.; Echols, I.; Zhao, X.; Radovic, M.; Green, M.J.; Lutkenhaus, J.L. Water Sorption in MXene/Polyelectrolyte Multilayers for Ultrafast Humidity Sensing. ACS Appl. Nano Mater. 2019, 2, 948-955. [CrossRef]

27. Wang, L.; Zhang, M.; Yang, B.; Tan, J.; Ding, X. Highly Compressible, Thermally Stable, Light- Weight, and Robust Aramid Nano Fibers $/ \mathrm{Ti}_{3} \mathrm{AlC}_{2}$ MXene Composite Aerogel for Sensitive Pressure Sensor. ACS Nano 2020, 14, 10633-10647. [CrossRef] [PubMed]

28. Shi, X.; Wang, H.; Xie, X.; Xue, Q.; Zhang, J.; Kang, S.; Wang, C.; Liang, J.; Chen, Y. Bioinspired Ultrasensitive and Stretchable MXene-Based Strain Sensor via Nacre-Mimetic Microscale "Brick-and-Mortar" Architecture. ACS Nano 2019, 13, 649-659. [CrossRef] [PubMed]

29. Cai, Y.; Shen, J.; Ge, G.; Zhang, Y.; Jin, W.; Huang, W.; Shao, J.; Yang, J.; Dong, X. Stretchable $\mathrm{Ti}_{3} \mathrm{C}_{2} \mathrm{~T}_{\mathrm{x}}$ MXene/Carbon Nanotube Composite Based Strain Sensor with Ultrahigh Sensitivity and Tunable Sensing Range. ACS Nano 2018, 12, 56-62. [CrossRef] [PubMed]

30. Chakraborty, I.; Bodurtha, K.J.; Heeder, N.J.; Godfrin, M.P.; Tripathi, A.; Hurt, R.H.; Shukla, A.; Bose, A. Massive Electrical Conductivity Enhancement of Multilayer Graphene/Polystyrene Composites Using a Nonconductive Filler. ACS Appl. Mater. Interfaces 2014, 6, 16472-16475. [CrossRef] [PubMed]

31. Seyedin, S.; Uzun, S.; Levitt, A.; Anasori, B.; Dion, G.; Gogotsi, Y.; Razal, J.M. MXene Composite and Coaxial Fibers with High Stretchability and Conductivity for Wearable Strain Sensing Textiles. Adv. Funct. Mater. 2020, 30, 1910504. [CrossRef]

32. Shi, X.; Liu, S.; Sun, Y.; Liang, J.; Chen, Y. Lowering Internal Friction of 0D-1D-2D Ternary Nanocomposite-Based Strain Sensor by Fullerene to Boost the Sensing Performance. Adv. Funct. Mater. 2018, 28, 1800850. [CrossRef]

33. Georgousis, G.; Pandis, C.; Kalamiotis, A.; Georgiopoulos, P.; Kyritsis, A.; Kontou, E.; Pissis, P.; Micusik, M.; Czanikova, K.; Kulicek, J.; et al. Strain Sensing in Polymer/Carbon Nanotube Composites by Electrical Resistance Measurement. Compos. PART B 2015, 68, 162-169. [CrossRef]

34. Rizzi, L.; Zienert, A.; Schuster, J.; Kóhne, M.; Schulz, S.E. Electrical Conductivity Modeling of Graphene-Based Conductor Materials. ACS Appl. Mater. Interfaces 2018, 10, 43088-43094. [CrossRef]

35. Clark, K.W.; Zhang, X.; Vlassiouk, I.V.; He, G.; Feenstra, R.M.; Li, A. Spatially Resolved Mapping of Electrical Conductivity across Individual Domain (Grain) Boundaries in Graphene. ACS Nano 2013, 7, 7956-7966. [CrossRef]

36. Hu, N.; Karube, Y.; Yan, C.; Masuda, Z.; Fukunaga, H. Tunneling Effect in a Polymer/Carbon Nanotube Nanocomposite Strain Sensor. Acta Mater. 2008, 56, 2929-2936. [CrossRef]

37. Martinez-Luengo, M.; Kolios, A.; Wang, L. Structural Health Monitoring of Offshore Wind Turbines: A Review through the Statistical Pattern Recognition Paradigm. Renew. Sustain. Energy Rev. 2016, 64, 91-105. [CrossRef]

38. Du, Y.; Zhou, S.; Jing, X.; Peng, Y.; Wu, H.; Kwok, N. Damage Detection Techniques for Wind Turbine Blades: A Review. Mech. Syst. Signal Process. 2020, 141, 106445. [CrossRef] 
39. García-Miquel, H.; Barrera, D.; Amat, R.; Kurlyandskaya, G.V.; Sales, S. Magnetic Actuator Based on Giant Magnetostrictive Material Terfenol-D with Strain and Temperature Monitoring Using FBG Optical Sensor. Measurement 2016, 80, 201-206. [CrossRef]

40. Zhang, C.J.; Anasori, B.; Seral-Ascaso, A.; Park, S.; Mcevoy, N.; Shmeliov, A.; Duesberg, G.S.; Coleman, J.N.; Gogotsi, Y.; Nicolosi, V. Transparent, Flexible, and Conductive 2D Titanium Carbide (MXene) Films with High Volumetric Capacitance. Adv. Mater. 2017, 29, 1702678. [CrossRef]

41. Hassan, G.; Bae, J.; Hassan, A.; Ali, S.; Lee, C.H.; Yohan Choi, Y. Ink-Jet Printed Stretchable Strain Sensor Based on Graphene/ZnO Composite on Micro-Random Ridged PDMS Substrate. Compos. Part A 2018, 107, 519-528. [CrossRef]

42. Ling, Z.; Ren, C.E.; Zhao, M.-Q.; Yang, J.; Giammarco, J.M.; Qiu, J.; Barsoum, M.W.; Gogotsi, Y. Flexible and Conductive MXene Films and Nanocomposites with High Capacitance. Proc. Natl. Acad. Sci. USA 2014, 111, 16676-16681. [CrossRef] [PubMed]

43. Fan, Z.; He, H.; Yu, J.; Liu, L.; Liu, Y.; Xie, Z. Lightweight Three-Dimensional Cellular MXene Film for Superior Energy Storage and Electromagnetic Interference Shielding. ACS Appl. Energy Mater. 2020. [CrossRef]

44. Habib, T.; Zhao, X.; Shah, S.A.; Chen, Y.; Sun, W.; An, H.; Lutkenhaus, J.L.; Radovic, M.; Green, M.J. Oxidation stability of Ti ${ }_{3} \mathrm{C}_{2} \mathrm{~T}_{\mathrm{x}}$ MXene nanosheets in solvents and composite films. npj 2D Mater. Appl. 2019, 3, 8. [CrossRef]

45. Novoselova, I.P.; Petruhins, A.; Wiedwald, U.; Weller, D.; Rosen, J.; Farle, M.; Salikhov, R. Long-Term Stability and Thickness Dependence of Magnetism in Thin $\left(\mathrm{Cr}_{0.5} \mathrm{Mn}_{0.5}\right)_{2} \mathrm{GaC}$ MAX Phase Films. Mater. Res. Lett. 2019, 7, 159-163. [CrossRef]

46. Lee, Y.; Kim, S.J.; Kim, Y.-J.; Lim, Y.; Chae, Y.; Lee, B.-J.; Kim, Y.-T.; Han, H.; Gogotsi, Y.; Ahn, C.W. Oxidation-resistant titanium carbide MXene films. J. Mater. Chem. A 2020, 8, 573. [CrossRef]

47. Limbu, T.B.; Chitara, B.; Orlando, J.D.; Cervantes, M.Y.G.; Kumari, S.; Li, Q.; Tang, Y.; Yan, F. Green synthesis of reduced Ti ${ }_{3} C_{2} T_{x}$ MXene nanosheets with enhanced conductivity, oxidation stability, and SERS activity. J. Mater. Chem. C 2020, 8, 4722. [CrossRef]

48. Zhou, B.; Zhang, Z.; Li, Y.; Han, G.; Feng, Y.; Wang, B.; Zhang, D.; Ma, J.; Liu, C. Flexible, Robust, and Multifunctional Electromagnetic Interference Shielding Film with Alternating Cellulose Nanofiber and MXene Layers. ACS Appl. Mater. Interfaces 2020, 12, 4895-4905. [CrossRef] [PubMed]

49. Yang, W.; Liu, J.-J.; Wang, L.-L.; Wang, W.; Yuen, A.C.Y.; Yuen, Y.; Peng, S.; Yu, B.; Lu, H.-D.; Yeoh, G.H.; et al. Multifunctional MXene/Natural Rubber Composite Films with Exceptional Flexibility and Durability. Compos. Part B 2020, 188, 107875. [CrossRef]

50. Chertopalov, S.; Mochalin, V.N. Environment-Sensitive Photoresponse of Spontaneously Partially Oxidized Ti ${ }_{3} \mathrm{C}_{2} \mathrm{MXene}^{\mathrm{T}} \mathrm{Thin}$ Films. ACS Nano 2018, 12, 6109-6116. [CrossRef] [PubMed] 